\title{
Intensive Mentoring and Micro-Electronics Research for Students in Engi- neering (IMMERSE)
}

\section{Prof. Stephen Schultz, Brigham Young University}

Stephen M. Schultz has received B.S. and M.S. degrees in electrical engineering from Brigham Young University, Provo, UT, in 1992 and 1994, respectively. He received a Ph.D. in electrical engineering from the Georgia Institute of Technology, Atlanta, GA, in 1999. He worked at Raytheon Missile Systems from 1999-2001. He has taught at Brigham Young University since 2002 and is currently a Full Professor. He has authored or coauthored over 100 publications and holds 10 patents. His research interests are in the area of optical fiber devices with an emphasis on optical fiber based sensors.

\section{Prof. Aaron R. Hawkins, Brigham Young University}

Aaron R. Hawkins received the B.S. degree in applied physics from the California Institute of Technology, CA, USA, in 1994, and the M.S. and Ph.D. degrees in electrical and computer engineering from the University of California, Santa Barbara, CA, USA, in 1996 and 1998 respectively. He was a Co-Founder of Terabit Technology and was later at CIENA and Intel. He is currently a Professor with the Electrical and Computer Engineering Department, Brigham Young University, Provo, UT, USA. He has authored or coauthored over 300 technical publications. He is a Fellow of the IEEE and the OSA and currently the Vice President for Publications for the IEEE Photonics Society. 


\title{
Intensive Mentoring and Micro-Electronics Research for Students in Engineering (IMMERSE)
}

\begin{abstract}
This paper describes an undergraduate research program called IMMERSE that has been implemented in the Electrical and Computer Engineering Department at Brigham Young University. Approximately 50 students per year participate along with 12 faculty members. The objectives of the IMMERSE program are to prepare student to continue on to graduate school and to enable students to publish their research in peer-reviewed venues. The key features of the program are (1) a single point of entry, (2) long-term and authentic research experiences, (3) participation in a broader impact project, and (4) personal mentoring between students and faculty. Since its inception in 2003, the program has had 251 total student participants that have published 225 peer reviewed publications and 75\% have continued on to graduate school.
\end{abstract}

\section{Introduction}

A recent report analyzed what made students view their undergraduate education as being worth the cost [1]. The three largest factors were the following:

- "My professor cared about me as a person."

- "I had a mentor who encouraged me to pursue my goals and dreams."

- "I had at least one professor who made me excited about learning."

All of these factors can be achieved through undergraduate research. In addition to having a direct impact on the perceived value of education, undergraduate research also increases confidence, understanding, and the percentage of students who continue on to graduate school [2-4].

Engineering professionals require critical thinking, the ability to analyze problems, and the ability to make decisions in the face of complex knowledge [5-7]. There has recently been an emphasis in having students gain these skills through research and inquiry [8-10]. In addition, undergraduate research programs have been used to attract students to academic programs [1112]. However, with the growing number of students involved in research, it is harder to give each one an authentic and beneficial experience. There are some projects that are simply extended homework problems or term papers [13]. The most important factors that are needed in a transformational undergraduate research experience are (1) having a strong mentor relationship $[1,4,14]$, (2) having a long enough experience to attain the benefits [2,14] and (3) performing significant research [4].

This paper describes an undergraduate research program called Intensive Mentoring and MicroElectronics Research for Students in Engineering (IMMERSE), which can be used as a model for producing a transformational research experience. The IMMERSE program currently operates with approximately 50 students and 12 faculty mentors per year. The overriding objectives of IMMERSE are to prepare students for graduate school and to facilitate publishable research.

\section{Program Features}

The key features of the IMMERSE program are (1) a single point of entry, (2) long-term and authentic research experiences, (3) participation in a broader impacts project, and (4) personal 
mentoring between students and faculty. These four features are discussed in detail in this section.

\subsection{Single Entry Point}

Many undergraduate students are poorly informed about undergraduate research opportunities at their institutions. This lack of information can be a result of unadvertised positions being filled ad hoc as students interact with professors. One of the operating principles of the IMMERSE program is a formal, well-advertised application process. This application process, which is open to all students, results in a better mix of student aptitudes.

The result is to help prepare and influence students who are unaware of future opportunities or too shy to establish a student-faculty relationship. The formal application process also allows students to be admitted with a range of GPAs. The average grade point average (GPA) for the IMMERSE participants for 2017 was 3.7. Figure 1 shows that even though the average GPA is biased towards the higher range, there is a wide distribution. While GPA is considered in the admission process, it is not the only factor and every year some students with a GPA in the range of $3.9-4.0$ are rejected.

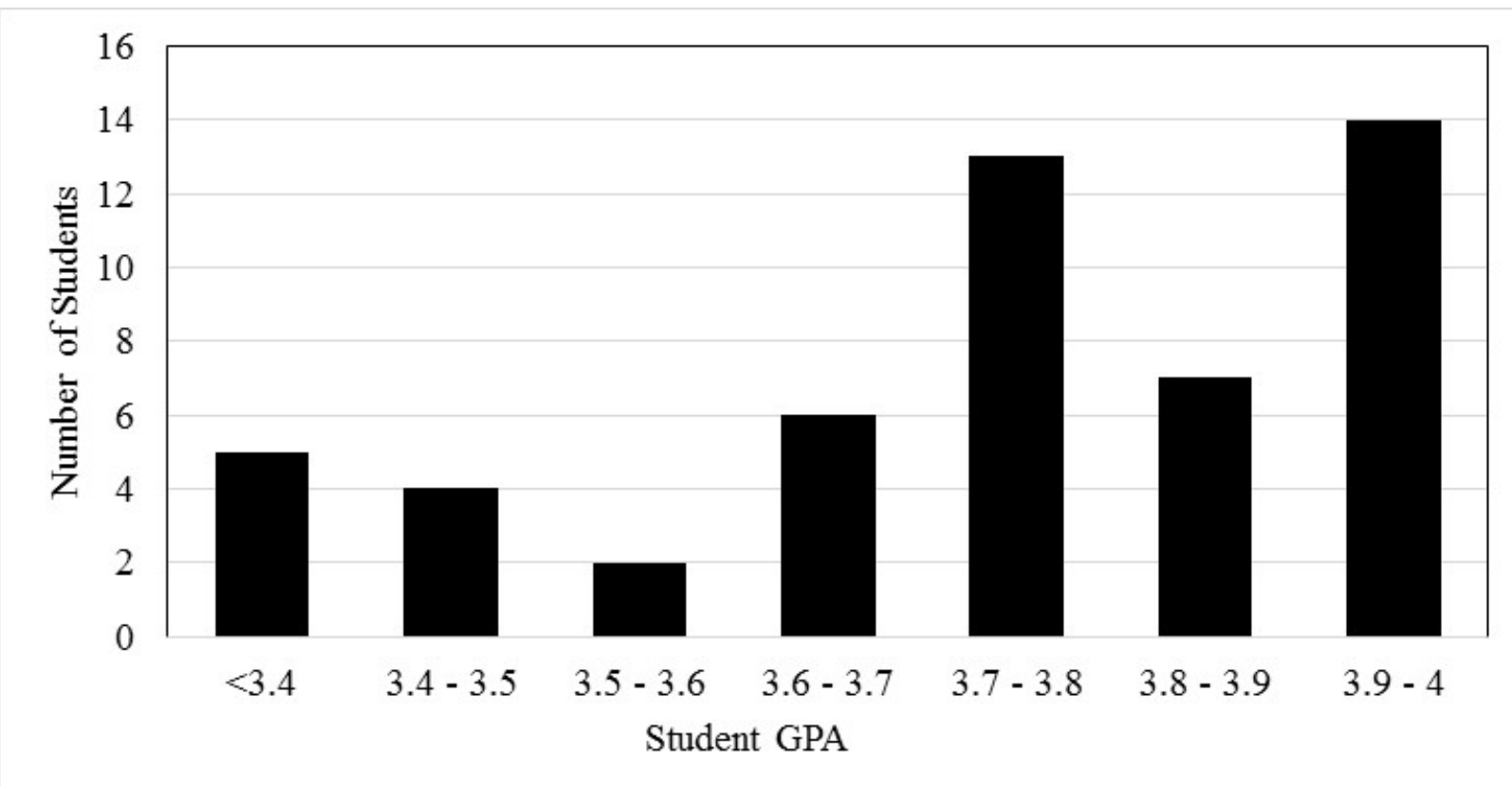

Figure 1. Histogram of IMMERSE participant GPA for 2017.

To streamline the application process, the IMMERSE program has an established webpage with information about the program. The webpage informs students about ongoing projects, expectations, and program structure. It also provides a central depository for information when advertising for the IMMERSE program through presentations and email.

\subsection{Authentic Research}

It has been determined that an 'authentic' research experience is needed for the students to attain the benefits of a research experience. Lila Guterman [4] provides examples of undergraduate 
research experiences where students spend most of their time washing glassware, weighing samples, etc. While these are necessary and important activities, they should not represent the entirety of a research experience. The factors that make the research 'authentic' are the following:

1. Long research experience: Thiry et al. [15] explains that there is a steep learning curve for students to learn the concepts underlying research projects. In order to have an authentic research experience, the students need to work on research long enough to overcome this learning curve. IMMERSE students are hired early in their undergraduate education to enable them to have a longer research experience. Typically, students are hired when they have two summers remaining before graduation. The students are mentored closely their first summer as they learn the specifics about their research project. During the second summer they can be much more productive and even function as a mentor to new IMMERSE students.

2. Students are placed into existing projects: In addition to having a long research experience, the learning curve is overcome by placing students into existing research projects. There are two advantages of placing students into existing research projects. First, the mentoring is better because there are existing students (both second year IMMERSE students and graduate students) that already understand the underlying concepts of the project. Second, this produces more value for the faculty mentor because it contributes to his or her existing research focus.

3. Maintain a reasonable undergraduate student faculty ratio: The IMMERSE program has grown by adding new faculty members rather than simply adding more students per faculty mentor. The IMMERSE program started in 2003 with two faculty members and grew gradually to its present size of twelve faculty mentors. While the number of students per faculty mentor can vary, it is usually held between two and ten to allow for adequate interaction with each student.

The following is a list of some example research projects in which IMMERSE students participated in 2017.

1. Liquid filled optical waveguides for on-chip chemical analysis: This research concentrates on optofluidic waveguides which can confine light in very low refractive index materials like water. Figure 2 shows an example of one of these structures used to probe fluids containing biologic particles such as viruses and DNA strands. The project involves collaborations with chemists and biologists at BYU, academic research groups at other universities, and commercial companies. The research aims to provide rapid tests for virus infections like Ebola and Zika and bacterial infections like the very dangerous drug-resistant bacteria strains which are becoming a bigger and bigger health risk. The end goal is the development of a portable instrument which can provide test results in less than one hour for many different virus and bacteria strains. 

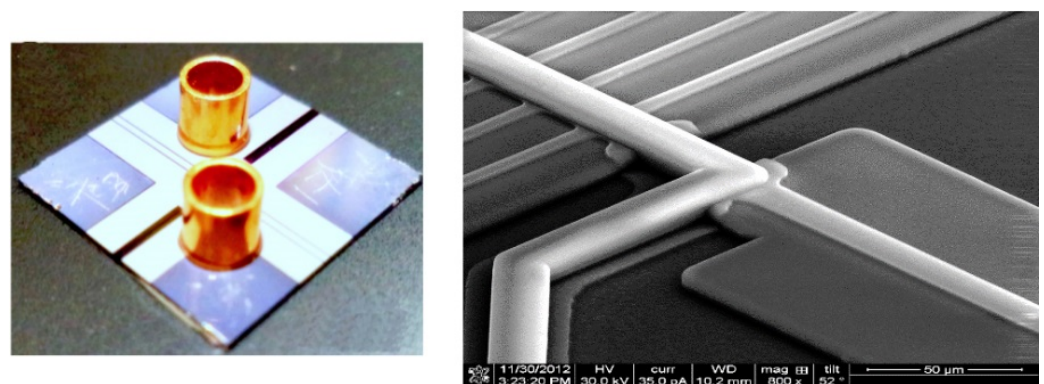

Figure 2. (Left) On-chip chemical analysis device and (right) scanning electron microscope image of the device.

2. Holographic Video Monitor: Figure 3 shows a low-cost holographic video monitor. This display differs from other electro-holographic display technologies in that it can be driven from a PC and has full color, VGA resolution and video rate operation. This is made possible by the use of low cost waveguide-based spatial light modulators.

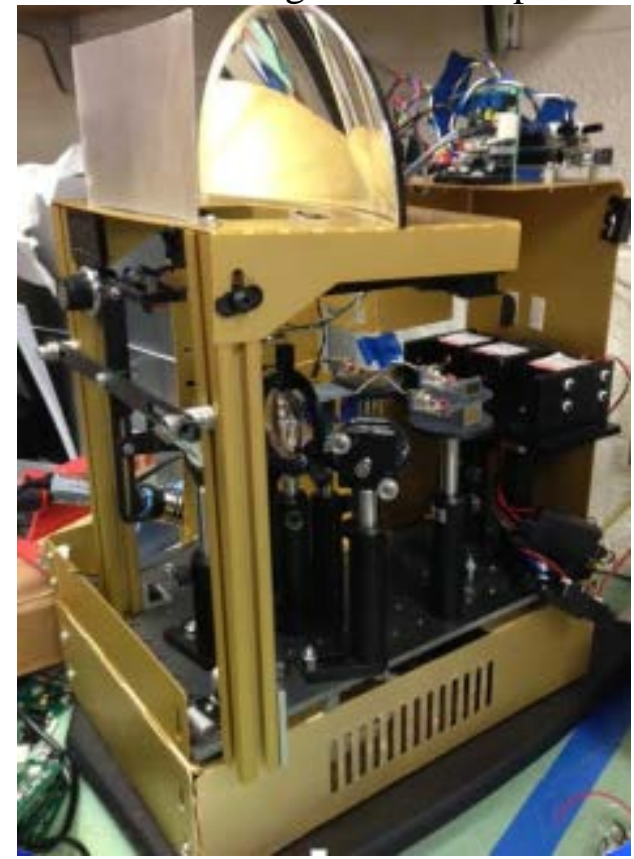

Figure 3. Holographic video display.

3. Concrete bridge deck scanning: Infrastructure deterioration is a pressing problem facing modern societies. In particular, reinforced concrete bridge decks are susceptible to corrosion because of frequent application of deicing salt during winter months. The objective of this research is to develop fast, accurate scanning solutions using electrochemical and acoustic techniques to rapidly evaluate the condition of bridge decks. Figure 4 shows a bridge scanning system with a super-imposed bridge scan. 


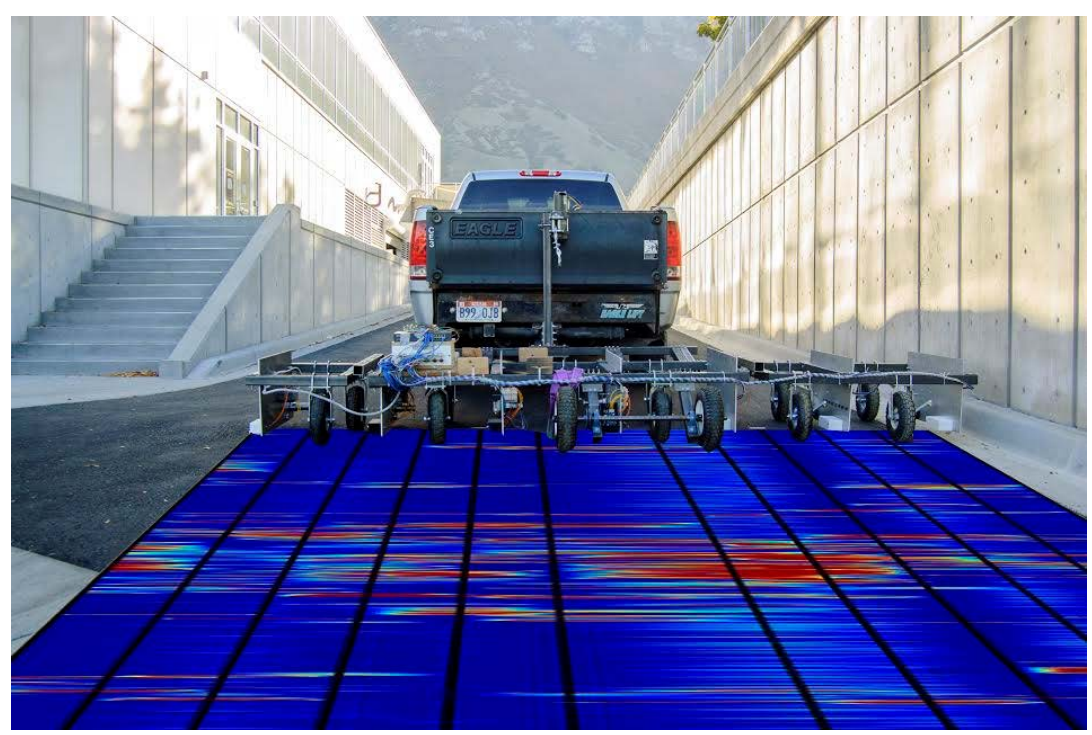

Figure 4. Bridge scanning.

4. Reliable FPGA computing: The growing use of satellites for complex communication, remote sensing, and surveillance applications requires significant computing resources. Modern satellites systems require far more computing power than ever before and there is a need to provide high-performance computing systems in spaces that are small, lightweight, reliable, and consume limited power. Field Programmable Gate Arrays (FPGAs) provide significant computing resources at the fraction of the power needed by conventional processor technologies. FPGAs, however, are sensitive to the ionizing radiation found in space environments and will not operate reliably unless appropriate radiation mitigation techniques are employed. This project is developing techniques for providing high-reliability, high-performance computing for space systems using FPGAs and other programmable technologies. This project is investigating novel reliability techniques, design tools, computer architecture approaches, and software for providing the most reliable deployment of FPGA-based systems. The results from this work are directly applicable to high-reliable computing in conventional environments on earth as well as within high-energy physics experiments such as the Large Hadron Collider.

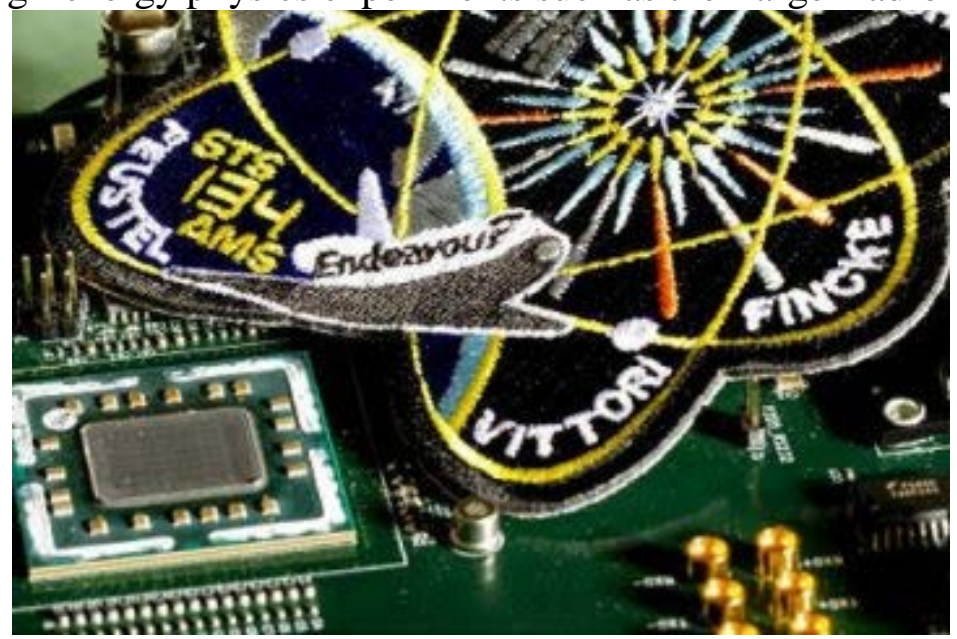

Figure 5. FPGA designed for reliable space applications. 
5. Optical fiber sensing for body armor testing: This research involves weaving an optical fiber sensors into a Kevlar woven fabric for the dynamic characterization of soft body armor during ballistic testing. Figure 6 show a Kevlar fabric with a woven optical fiber after a ballistic shot.

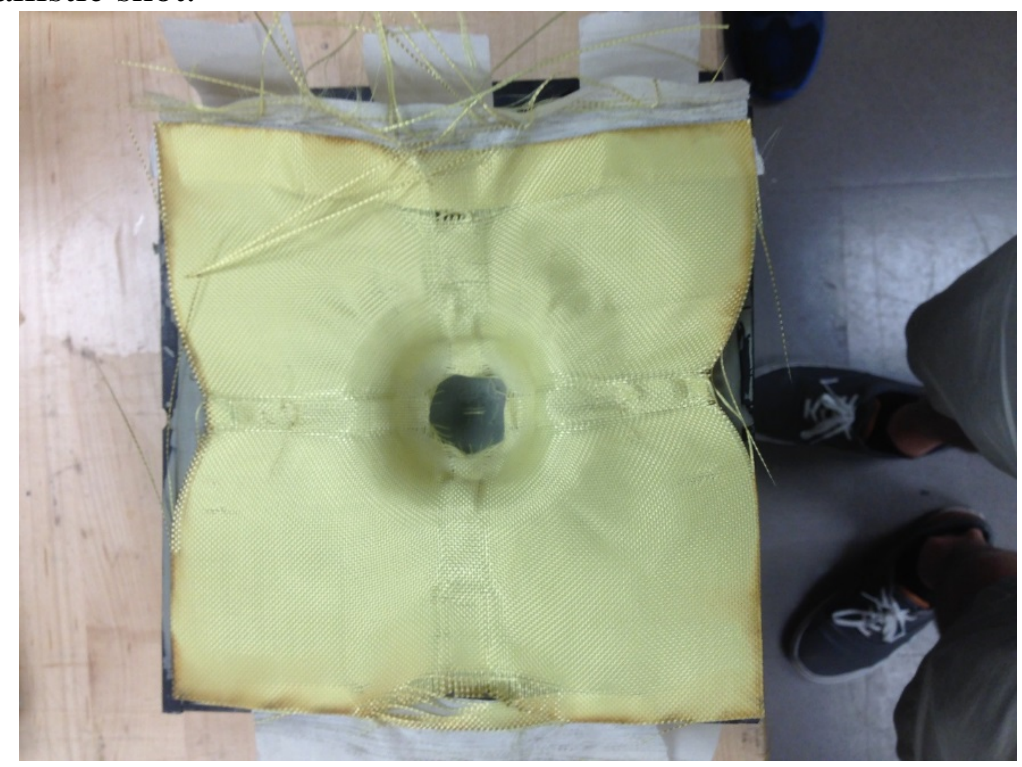

Figure 6. Kevlar fabric with woven optical fiber sensor.

6. 3D phase sensitive B1 mapping for MRI imaging: Sodium MRI can be used to assess cartilage health, characterize tumors, detect abnormal sodium levels in the kidneys, and to assess tissue damage following a stroke. However low sodium concentration in tissues, a rapid exponential decay and a low gyro-magnetic ratio makes sodium MRI more challenging. The new Phase Sensitive B1 mapping technique describes B1 homogeneity better than the standard dual angle method and for a broader range of flip angles under high noise situations. Thus, Phase Sensitive B1 mapping is a much better candidate for sodium MRI, with high noise and large B1 variation.

7. Micropower circuit design: The Micropower Circuits Laboratory (MCL) investigates ultra-low-power designs for RF/analog/mixed-signal integrated circuits. Emphasizing both rigorous analysis and intuitive understanding of circuits, MCL's research seeks innovative designs to set new low-power records. Research projects include ultra-lowpower analog front-end circuits, energy-efficient data converters, and novel signalacquisition and conditioning circuits for biomedical devices and communication systems. Figure 7 shows a simplified schematic for a micropower circuit. 


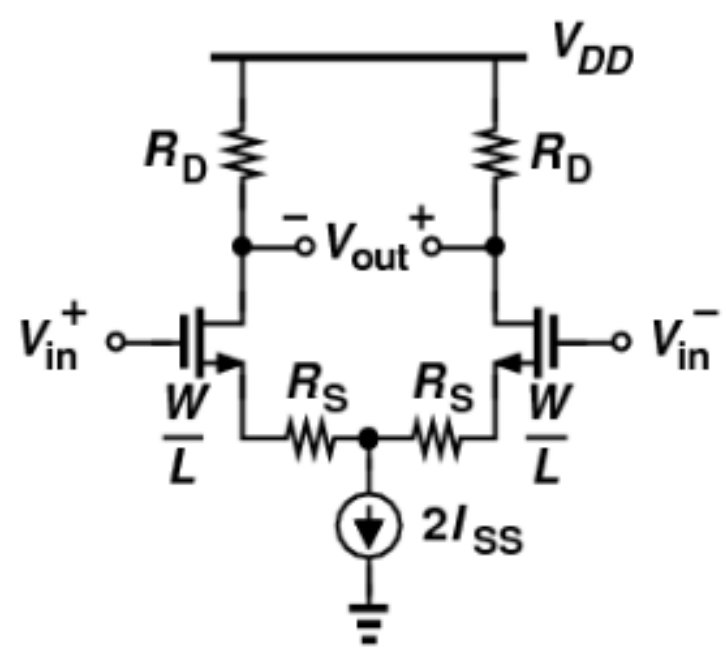

Figure 7. Schematic of a micropower circuit.

\subsection{Broader Impact}

Another unique feature of the IMMERSE program is that broader impact projects are integrated into with research projects. These broader impact projects include developing online resources, developing hands-on displays and demonstrations, and an engineering summer camp for seventh and eighth grade students called Chip Camp.

There are two main purposes for the Broader Impacts projects. First, these projects tend to be fun and engaging for the IMMERSE students. Spending some time working on these easy to grasp projects helps the students build confidence. It also helps motivate the importance of engineering, which in turn helps encourage them to struggle through a difficult engineering curriculum or research project. Currently, IMMERSE participant are divided into three Broader Impacts groups: (1) Outreach, (2) Websites, and (3) Chip Camp.

The Outreach group is involved in developing demonstrations that can be used to educate the general public, new students, or prospective students about electrical and computer engineering. Figure 8 shows an IMMERSE student (with the blue t-shirt) participating with the Summer Of Academic Refinement (SOAR) program that is a college preparation program run by the Multicultural Student Services Office. Figure 9 shows one of the interactive displays being used during a community outreach activity.

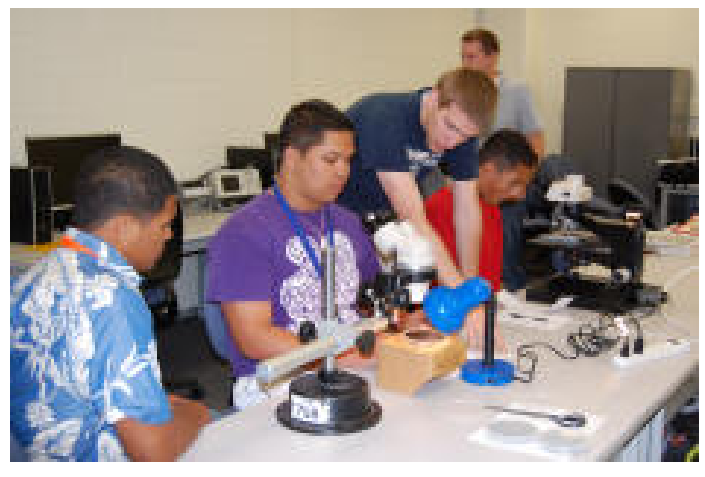

Figure 8. Picture of an activity from the Summer Of Academic Refinement (SOAR) program. 


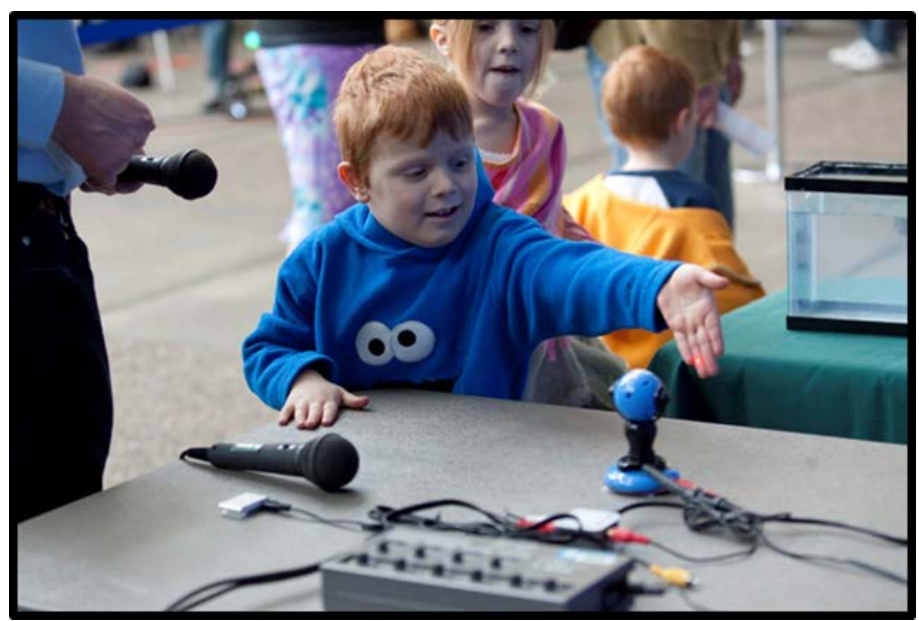

Figure 9. Interactive display.

The Websites group is involved in developing online resources. These resources include operating procedures for equipment used in the cleanroom. The cleanroom website also includes standard microfabrication process recipes, online calculators, etc.

The Chip Camp group is by far the largest of the Broader Impact groups. During the two weeks of the engineering camp, all of the IMMERSE participants help run the various activities or function as group counselors. Figure 10 shows a Chip Camp banner used for advertising.

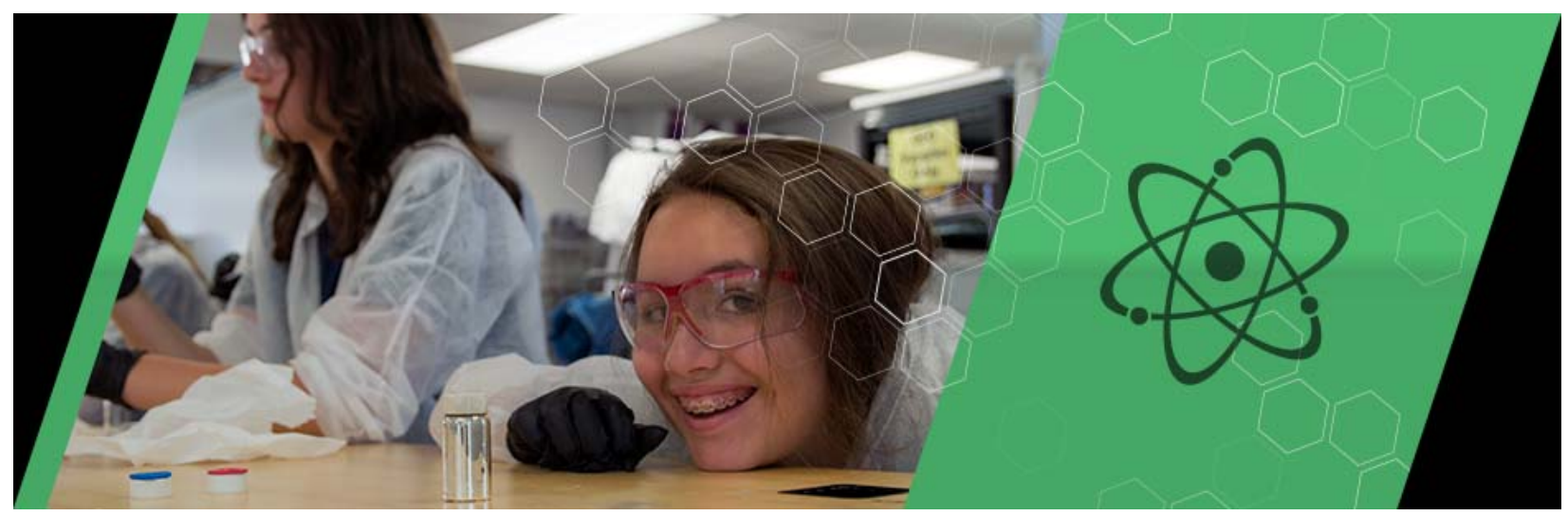

Figure 10. Chip Camp banner.

Chip Camp is divided into three days of learning activities with three overlapping groups of $7^{\text {th }}$ and $8^{\text {th }}$ grade students. The camp runs from 9 am to $4 \mathrm{pm}$ each day and lunch is provided. A few of the 14 learning activities are listed here.

1. Circuits: Figure 11 shows how the students build their own switches using aluminum foil and foam. The switches are then connected to a Dance Dance Revolution system to test the switches and how they fit into a simple circuit. 

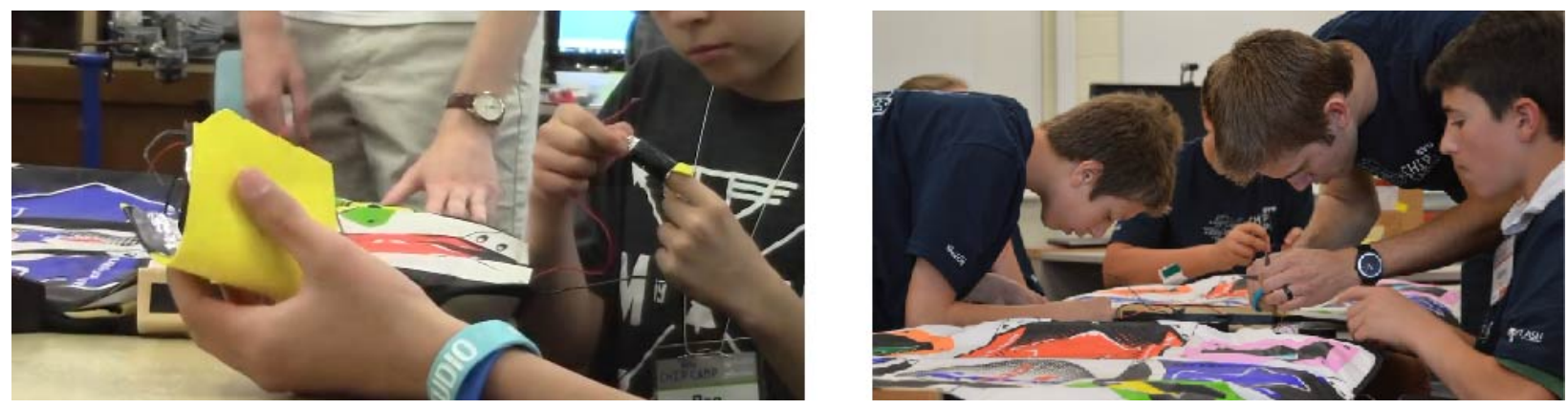

Figure 11. Chip Camp circuit design activity involving building switches and connecting them to a Dance Dance Revolution system.

2. Statistics: Figure 12a shows catapults that are used to teach probability and statistics. In this activity there are three different settings (rubber band strength, ball placement, and catapult angle). The students do experiments to predict where the ball will land for a specific set of parameters.

3. Design Optimization: Figure 12b shows the paper rockets that the students design and build to determine how to get the rockets to fly the farthest distance or hit a designated target.

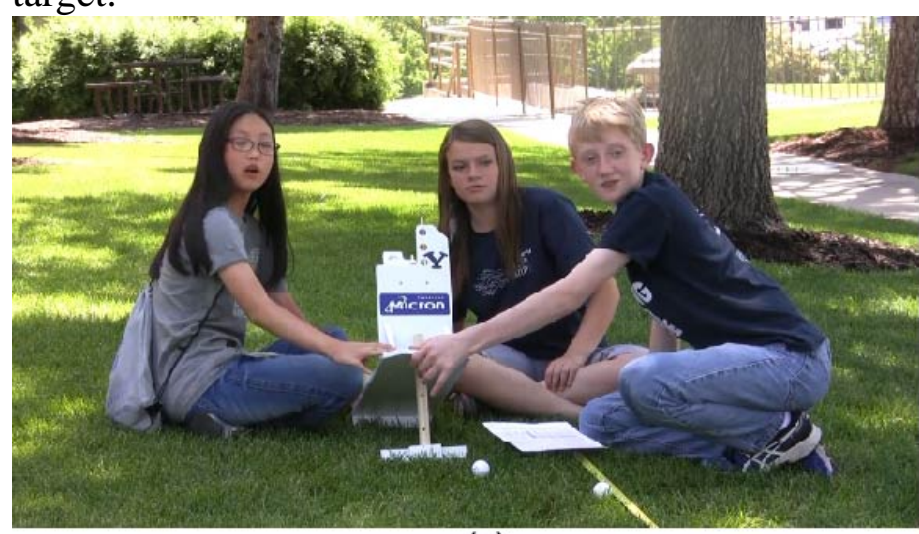

(a)

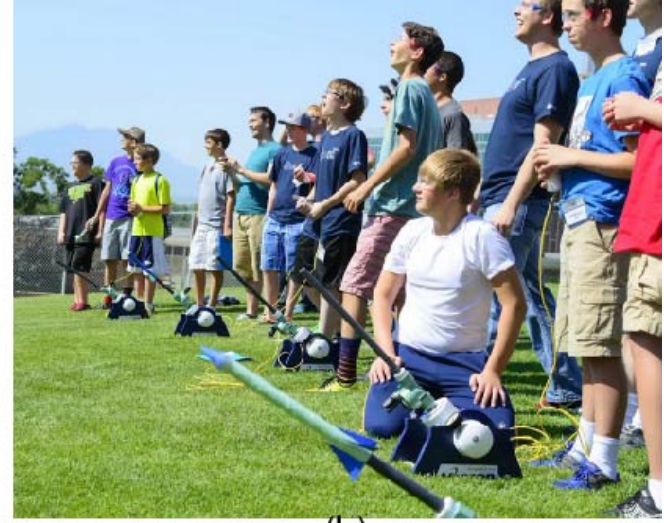

(b)

Figure 12. (a) Teaching statistic using catapults. (b) Teaching the design process using compressed air paper rockets.

4. Material deposition: Figure 13a shows the participants learning about chemical reactions as they perform a deposition process to coat a glass vial with a layer of silver.

5. Photolithography: The students learn basic microfabrication processes including photolithography. As part of this activity, the students dress in protective clothing and tour the cleanroom where they are taught about microchip fabrication. Figure 13b shows one of the groups in the cleanroom holding quarters that have been coated in gold using one of the cleanroom's metal evaporators. 


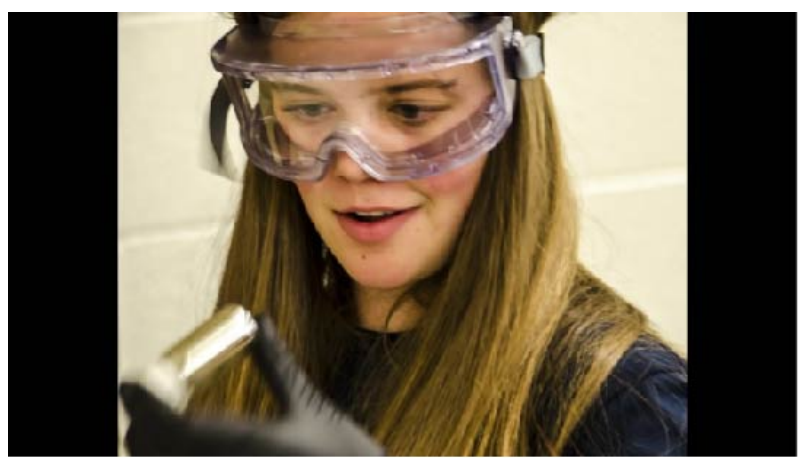

(a)

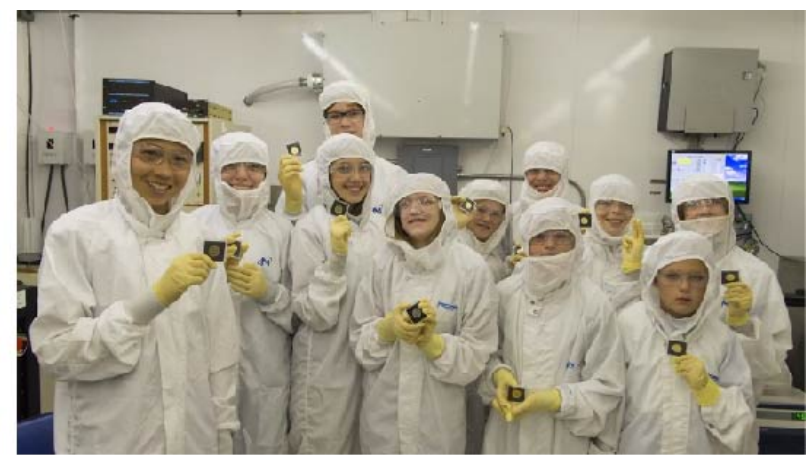

(b)

Figure 13. (a) Chemistry activity involving coating the inside of a vial with silver. (b) Cleanroom activity where the participants learn about photolithography and thin film evaporation.

6. Programming: Figure 14 shows a circuit board attached to a Frisbee. The circuit boards have six RGB LEDs and a Texas Instruments programmable microcontroller. Chip Camp students learn to do simple programming to produce interesting light patterns when the Frisbees spin.
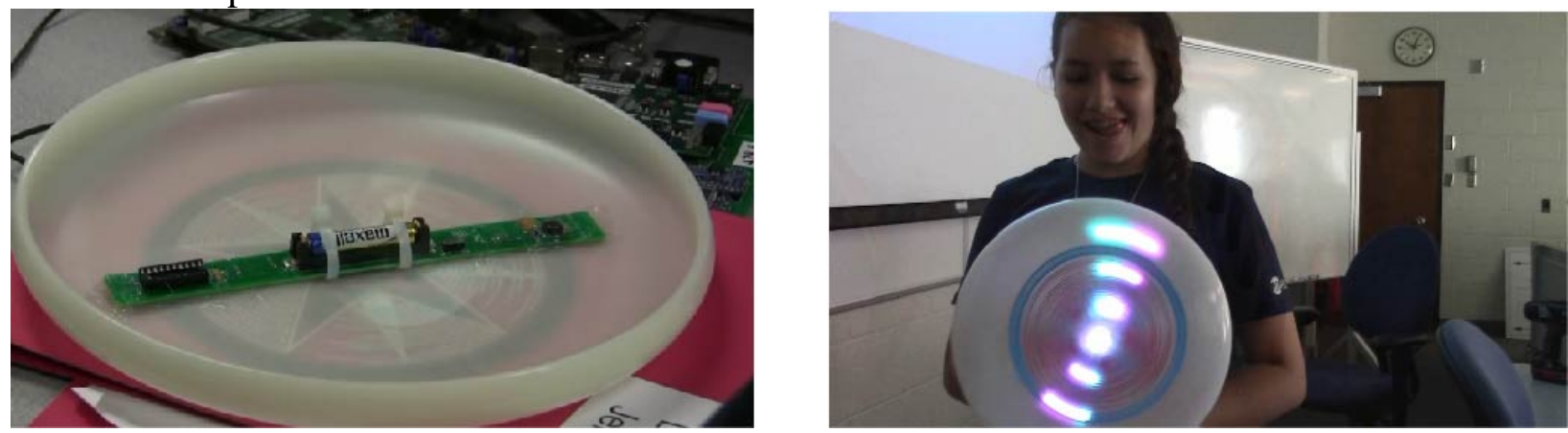

Figure 14. Programming activity to make color patterns using a spinning Frisbee equipped with programmable LEDs.

\subsection{Personal Mentoring}

Each student in IMMERSE is assigned to a research project under a faculty member [16-17]. In addition, a new undergraduate research student is assigned a more senior student mentor that works closely with the new student [18]. The IMMERSE program has a uniform start date at the beginning of the summer which allows students to dedicate a significant amount of time to training and understanding the research project to which they are assigned. There are three components to the mentoring environment.

1. Group Meeting: During the summer there are weekly group meeting consisting of all faculty mentors and all of the undergraduate student participants. The two parts to these group meeting are instruction by the faculty members and technical student presentations.

The following are a list of lecture topics presented by faculty members: (a) How to give a technical oral presentation. (b) How and where to publish a paper. (c) How to assemble and write a technical paper. (d) How to find and use reference articles. (e) Applying to graduate 
school. (f) Applying for fellowships. (g) Engineering ethics. (h) Is graduate school right for you? (i) Networking in school and your career.

Each IMMERSE student gives a technical presentation during the summer group meeting (see Figure 15), which provides a supportive atmosphere consisting mostly of their peers. These presentations help students improve communications skills and put their specific research into a "big picture" context. After the presentation, audience members give suggestions on what they liked about the presentation and what could be improved.

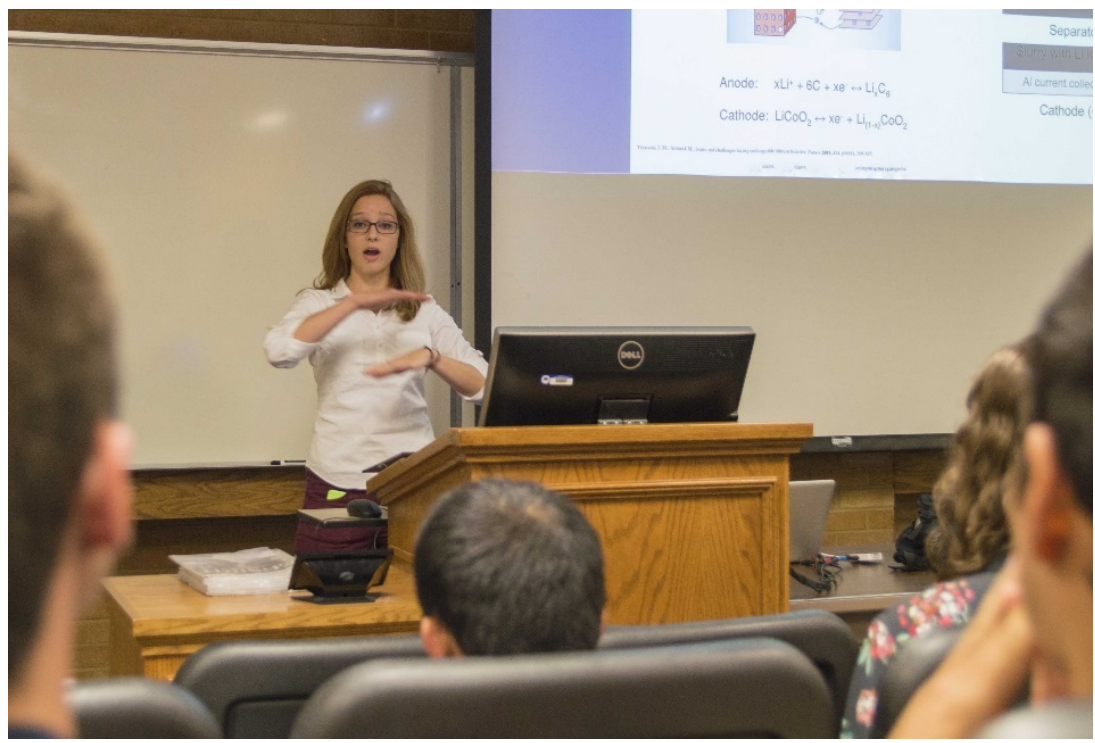

Figure 15. Student presentation during an IMMERSE group meeting.

2. Individual Research Meetings: Student research projects are divided between faculty members. Faculty hold individual meetings (at least weekly) with the students involved in the project. Students work in small teams structured to provide a stimulating learning experience for the student and be of relevance to contemporary electrical and computer engineering. Faculty members and graduate students mentor students in each of these projects. Individual research topics tend to overlap with at least one other project. This overlap encourages interaction between the students working on related projects. This student interaction provides additional peer-to-peer mentoring between students and encourages them to work in teams to solve technical problems. We have discovered from past experiences that a great deal of camaraderie develops between IMMERSE students (no matter how diverse their research topics), which lasts throughout their undergraduate careers and into their graduate careers.

Individual research meetings include progress reports given by each of the students involved. The purpose of reporting is two-fold. First, it provides a motivation to work diligently. Second, through regular feedback, faculty members can ensure that work is progressing in the correct direction. These meetings are used to help resolve problems associated with particular projects and will enable the students to learn directly from faculty members. The individual nature of these meetings will facilitate more informal instruction. 
3. Broader Impacts Meeting: The undergraduate researchers also attend a weekly meeting where they discuss their progress on Broader Impact projects.

\section{Program Results}

The stated objectives of the IMMERSE program are to prepare students to continue on to graduate school and to allow students to conduct and publish significant research. Between 2003 and 2017, 251 undergraduate research students participated in IMMERSE. Eighty percent of IMMERSE students have been primary or co-authors on a total of 225 peer reviewed publications. These publications have been in a wide variety of peer reviewed journals relevant to electrical and computer engineering, such as Applied Optics, Applied Physics Letters, Lab on a Chip, Magnetic Resonance in Medicine, Journal of the Electrochemical Society, etc. The diverse nature of these publications demonstrates the diverse exposure of the IMMERSE participants to different research fields.

Approximately 75\% of IMMERSE students end up matriculating into graduate programs, primarily in the United States. Figure 16 shows the locations of graduate school destinations for IMMERSE students. This illustration is meant to demonstrate that the IMMERSE program prepares students to go to a wide range of different universities across the United States.

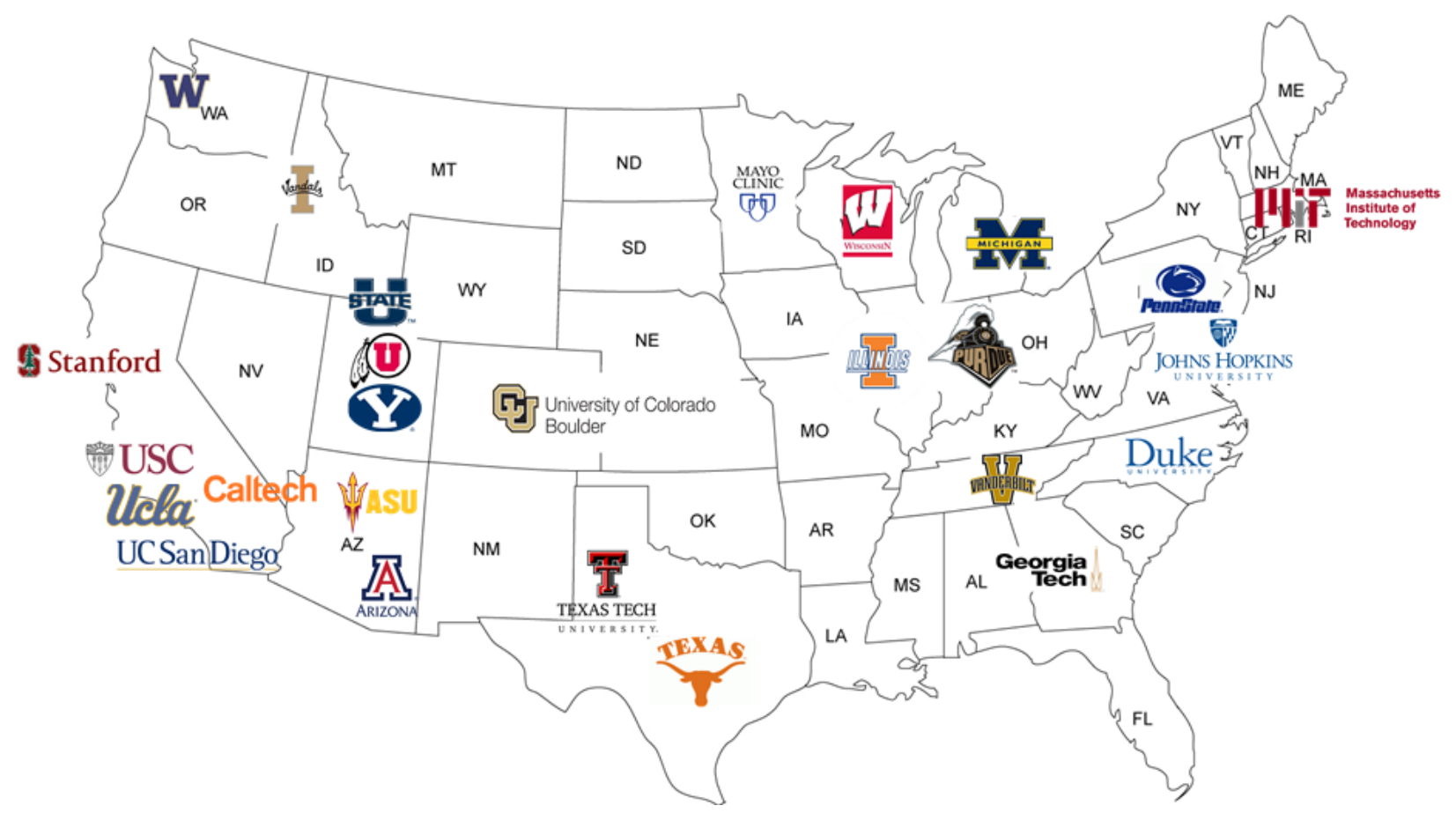

Figure 16. Illustration of where the IMMERSE participants have attended graduate school.

In order to assess how effectively the IMMERSE program influences graduate school attendance, an anonymous online survey was conducted among students who participated in the years 2016 and 2017. Figure 17 shows the results of this survey, with more than 75\% of the students indicating that their interest in attending graduate school increased because of the program. 


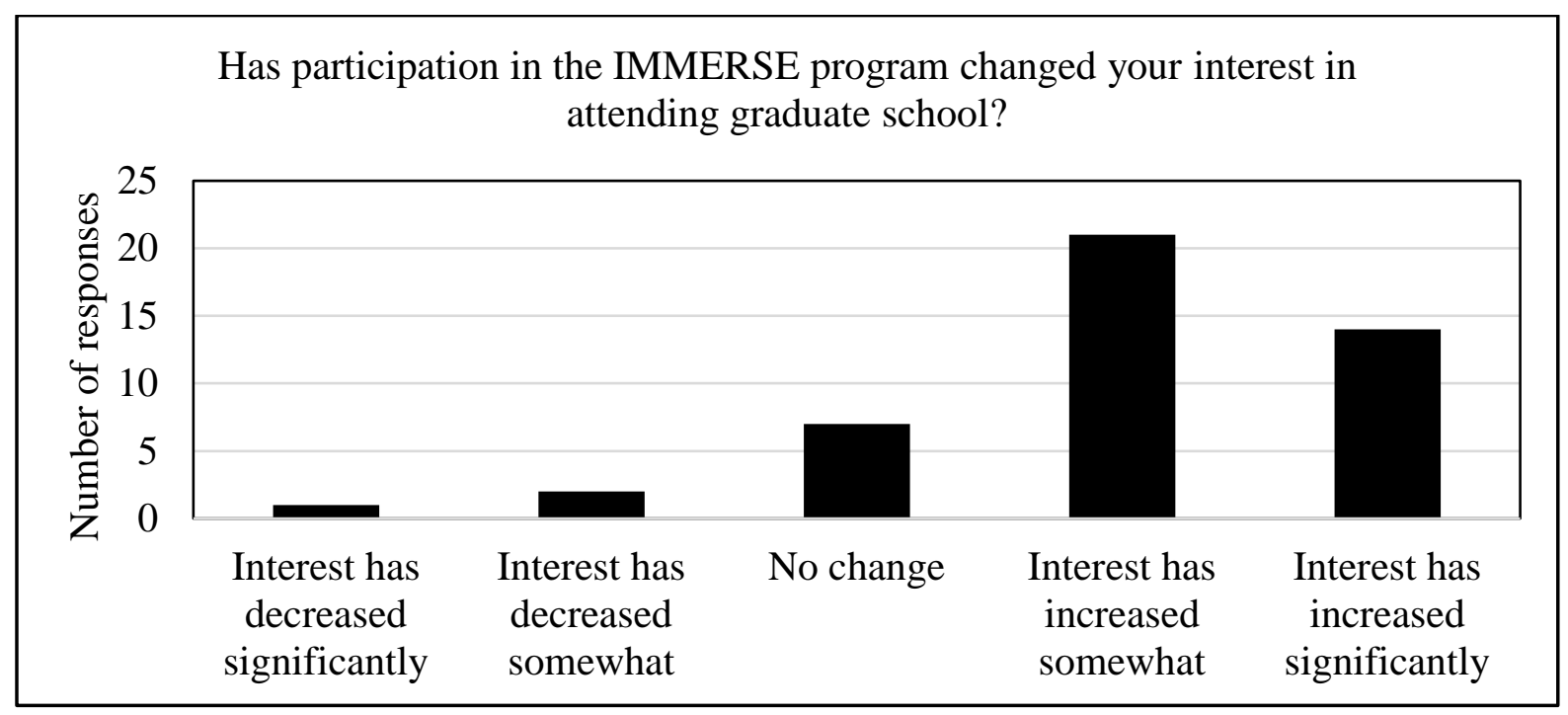

Figure 17. Survey response about how the IMMERSE program has influenced their decision to attend graduate school.

Also of importance is whether the IMMERSE program increased participant interest in pursuing a Ph.D. degree. Figure 18 shows that for those students inclined to go to graduate school, over $40 \%$ of them were more inclined to pursue a Ph.D. rather than an M.S. after participating in the IMMERSE program.

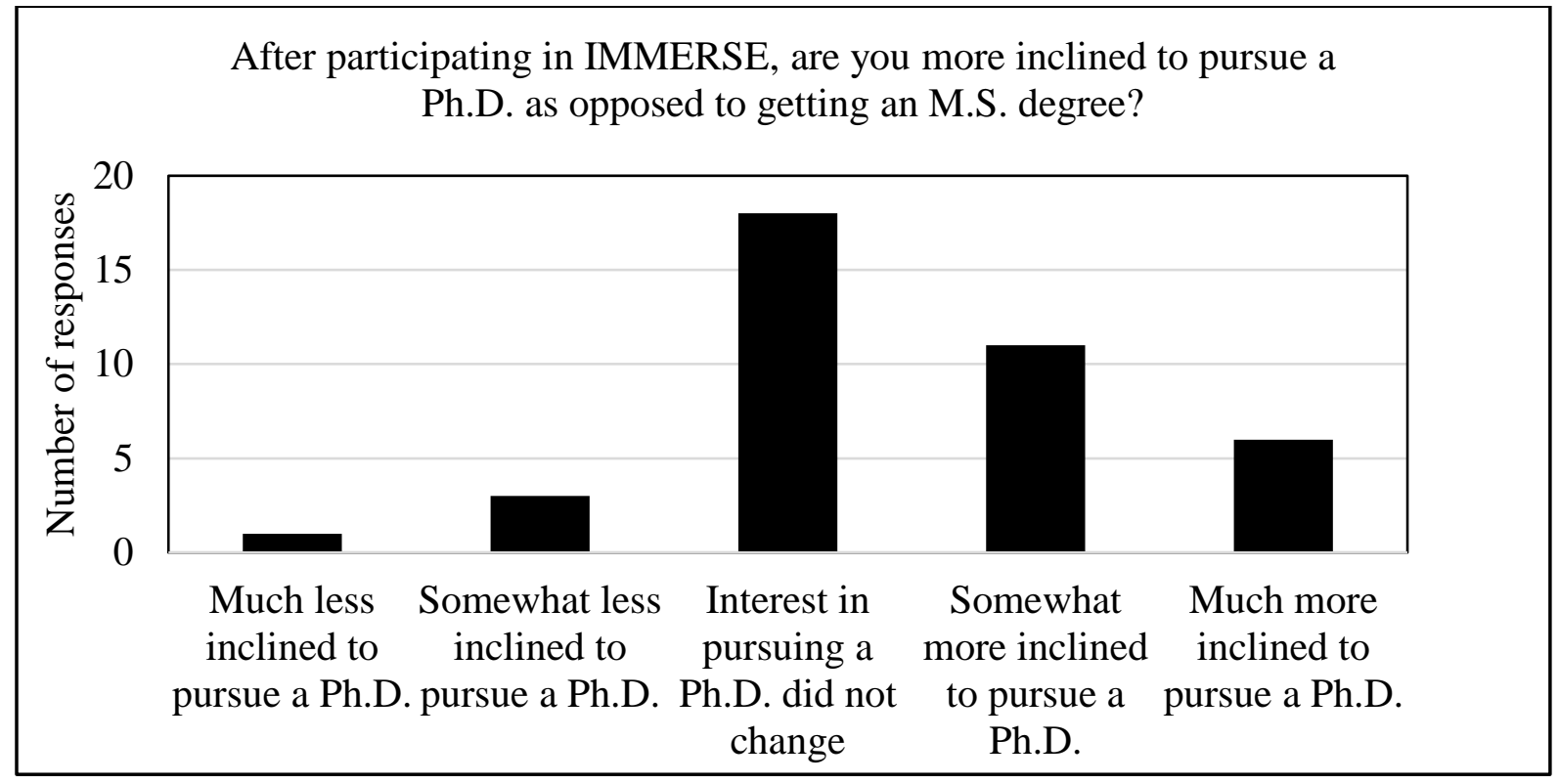

Figure 18. Survey response about how the IMMERSE program has influenced the desire to pursue at Ph.D.

The Broader Impacts projects have also produced tangible results. For instance, the cleanroom website averages around 100k site visits per month with about $90 \%$ of these visits from users external to the university. Perhaps our most visible project, Chip Camp, has been offered for the 
last five years and enrollment numbers continue to rise. In 2017, Chip Camp accommodated 160 $7^{\text {th }}$ and $8^{\text {th }}$ grade students with an interest in engineering.

\section{Funding}

The IMMERSE program pays a fixed stipend to each faculty mentor for each undergraduate participant. The stipend usually pays approximately one third of the cost of an undergraduate researcher's summer salary. The other two thirds of their salary is typically paid through external research contracts. The stipend funds come from a variety of different sources including money from the university earmarked for experiential learning experience, department endowment funds, Chip Camp tuition income, and industrial sponsors.

\section{Discussion and Conclusions}

The undergraduate research program called IMMERSE has four key aspects. (1) Single point entry with an online application process provides a better way for advertising of the program. It also provides more efficient initial research training. (2) Authentic research is attained by placing undergraduate researchers into existing projects, maintaining a reasonable studentfaculty ratio, and providing for a longer research length by recruiting students early in their university careers. (3) The participants are involved in a broader impacts project. The most visible broader impact project is an engineering summer camp for junior high students called Chip Camp. (4) Personal mentoring for the students is attained by assigning each student both a faculty mentor and a student mentor. Mentoring also takes place in weekly group meetings in the summer where there is faculty instruction and student research presentations.

There are several features of the IMMERSE program that are similar to other undergraduate research programs. For instance, we are not unique in recognizing the value of personal mentoring between undergraduate researchers, experienced students and faculty. Along with the proven value of mentoring, the need to integrate new undergraduate research students into existing research projects helps the participant to experience an authentic research experience and provides value to the faculty member to help offset some of the required mentoring time.

Like IMMERSE, there are some undergraduate research programs which encourage long-term participation $[14,15]$; however, many undergraduate research programs have a short length. Our experience is that it is difficult to perform authentic research without the extended length. This is supported by previous studies concerned with the length of undergraduate research experiences.

The most unique feature of the IMMERSE program is probably the combination of research projects with projects that emphasis “Engineering Broader Impact.” In addition to their research expectations, each student devotes $10-15 \%$ of their summer working hours to fun and engaging projects designed to build confidence, raise appreciation of the real-world value of engineering, and contribute to the engineering education of others. This aspect of IMMERSE is valuable because it provides the opportunity for participants to develop confidence in applying their engineering skills to straightforward, high visibility projects. This confidence boost is often important as students deal with the steep learning curve involved in many research projects. 


\section{References}

1. Gallup (Firm) Purdue University, "Great jobs, great lives: the relationship between student debt, experiences and perceptions of college worth." (2015)

2. S. Russell, M. Hancock, and J. McCullough, "Benefits of Undergraduate Research Experiences,” Science (Washington), 548-549. (2007)

3. P. Hunter, “Undergraduate research,” EMBO reports, 8, 717-719. (2007)

4. L. Guterman, “What Good Is Undergraduate Research, Anyway?” Chronicle of Higher Education, 53. (2007)

5. A. Brew, and L. Mantai, "Academics' perceptions of the challenges and barriers to implementing research-based experiences for undergraduates," Teaching in Higher Education, 1-18. (2017)

6. Wilson, S. Howitt, K. Wilson, and P. Roberts, “Academics’ Perceptions of the Purpose of Undergraduate Research Experiences in a Research-Intensive Degree,” Studies in Higher Education, 37, 513-526. (2012)

7. H. A. Wayment, and K. L. Dickson, “Increasing Student Participation in Undergraduate Research Benefits Students, Faculty, and Department,” Teaching of Psychology, 35, 194197. (2008)

8. A. Brew, "Teaching and Research: New Relationships and Their Implications for Inquiry Based Teaching and Learning in Higher Education," Higher Education Research and Development, 22, 3-18. (2003)

9. J. Hattie, and H. W. Marsh, "The Relationship between Research and Teaching: A Meta analysis,” Review of Educational Research, 66, 507-542. (1996)

10. M. Healey, and A. Jenkins, “Developing Undergraduate Research and Inquiry,” Higher Education Academy. (2009)

11. A. Brew, and J. Cahir, “Achieving Sustainability in Learning and Teaching Initiatives,” International Journal for Academic Development, 9, 341-352. (2014)

12. G. D. Kuh, "High-impact Educational Practices: What They Are, Who has Access to Them, and Why They Matter," Washington, DC: Association of American Colleges and Universities. (2008)

13. L. Reisberg, "Research by undergraduates proliferates, but is some of it just glorified homework,” The Chronicles of Higher Education, 20, A45-A46. (1998)

14. A. Zydney, J. Bennett, A. Shahidand K. Bauer, "Impact of undergraduate research experience in engineering,” Journal of Engineering Education, 91, 151-157. (2002) 
15. H. Thiry, T. Weston, S. Laursen, and A. Hunter, "The benefits of multi-year research experiences: differences in novice and experienced students' reported gains from undergraduate research," CBE-Life Sciences Education, 11, 260-272. (2012)

16. S. Hu, K. Scheuch, and J. G. Gayles, "The Influences of Faculty on Undergraduate Student Participation in Research and Creative Activities," Innovative Higher Education, 34, 173183. (2009)

17. S. J. E. Potter, E. Abrams, L. Townson, and J. E. Williams, "Mentoring Undergraduate Researchers: Faculty Mentors Perceptions of the Challenges and Benefits of the Research Relationship," Journal of College Teaching \& Learning, 6, 17-30. (2011)

18. E. Dolan, and D. Johnson, "Toward a Holistic View of Undergraduate Research Experiences: An Exploratory Study of Impact on Graduate/Postdoctoral Mentors,” Journal of Science Education and Technology, 18, 487-500. (2009) 